\title{
Prevalence of Anaphylaxis among children 3 to 18 years old in Kuweit
}

\author{
Abdaljabbar Farhan*1,2 \\ ${ }^{1}$ The New Mowasat Hospital, Kuwait \\ ${ }^{2}$ Faculty of Medicine, University of Southampton, Southampton, UK
}

Received: June 13, 2018; Published: June 20, 2018

*Corresponding author: Abdaljabbar Farhan, The New Mowasat Hospital, Kuwait and Faculty of Medicine, University of Southampton, Southampton, UK, Tel: 9715 57084949; Email: abdfarhan@yahoo.com

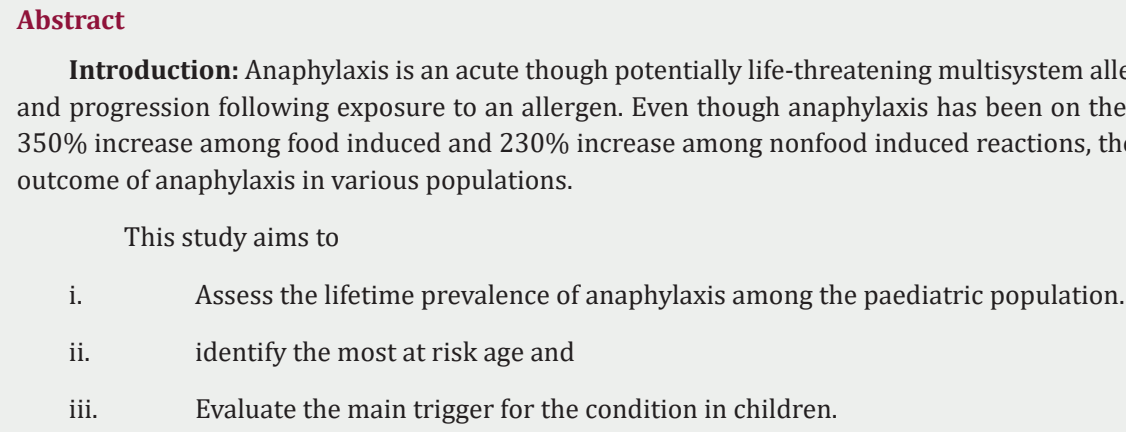
outcome of anaphylaxis in various populations.

This study aims to

i. Assess the lifetime prevalence of anaphylaxis among the paediatric population.

ii. $\quad$ identify the most at risk age and

iii. Evaluate the main trigger for the condition in children.

Introduction: Anaphylaxis is an acute though potentially life-threatening multisystem allergic reaction characterized by a rapid inception and progression following exposure to an allergen. Even though anaphylaxis has been on the rise for the past decade with reported rates of $350 \%$ increase among food induced and $230 \%$ increase among nonfood induced reactions, there is still paucity of data on the prevalence and

Methodology: A descriptive cross-sectional study with a multistage stratified cluster sampling of children aged three to eighteen was conducted in Kuwait. 2828 registered students of both genders and all nationalities in the selected governmental and private schools were sequentially recruited in the school years 2014-2015 and 2015-2016 over a period of 9 months to participate in the study.

Results: The overall prevalence of anaphylaxis in the study population was 4.24 per 1000 with a 95\% confidence interval of $1.85-6.64$ per 1000 population. A total of $12(0.42 \%)$ participants fulfilled all the criteria for diagnosing probable anaphylaxis, out of which $66.7 \%$ were diagnosed during the incidence by a medical physician. Food was the major trigger in 9 (75.0\%) children overall, of which nuts was the most common (33.3\%), followed equally by milk and egg (16.7\%) and another $16.7 \%$ for other types of unspecified food. Medicine was the trigger in $2(16.7 \%)$ of them and one was not sure of the trigger.

Conclusion: Anaphylaxis in children is a stimulating and challenging subject requiring targeted studies, starting with those assessing the prevalence of this emerging serious disease, to those highlighting the lack of availability, utilization and correct use of the treatment and the necessity of an emergency action plan.

\section{Introduction}

Anaphylaxis is an acute though potentially life-threatening multisystem allergic reaction characterized by a rapid inception and progression following exposure to an allergen. Hence, immediate diagnosis and treatment of the disease is critical. Anaphylaxis can be caused by a wide range of substances, namely food, medications, drugs, latex and insect prickles [1]. Diagnosis of anaphylaxis in patients presenting with classic sudden onset of signs and symptoms after exposure to a known trigger is mainly done through a review of the medical history in combination with a physical examination. In some cases, clinicians need to pay special attention to those patients who have not experienced an anaphylactic reaction previously as they may not be aware of the underlying trigger for their reac tion and may experience atypical signs and symptoms as opposed to the classic criteria [1]. Ideally, when symptoms are suggestive of anaphylaxis, increased serum tryptase drawn 15 minutes to 3 hours post onset of symptoms can confirm the diagnosis [2]. However, 3 hours past onset of clinical symptoms, laboratory confirmation becomes of limited value. Moreover, particularly in food allergies, normal tryptase levels do not exclude possible anaphylaxis. Optimally, a comparison of successive tryptase level measurements throughout an anaphylaxis reaction with baseline levels drawn after the anaphylactic reaction has resolved is more informative. Total and allergen-specific IgE and skin prick tests are other tools used to support suggestive anaphylaxis diagnosis, but are of limited value when performed in isolation. Rule of thumb for food allergy diagnosis is the double-blind, placebo controlled food challenge [3]. 
The Second National Institute of Allergy and Infectious Disease/Food Allergy and Anaphylaxis Network symposium convened in 2004 [4] and reconvened in July 2005 in the presence of various stakeholders in an attempt to close the gap and achieve universal consensus on the clinical criteria for anaphylaxis diagnosis [5]. Participants, namely the National Institute of Allergy and Infectious Diseases (NIAID), the European Academy of Allergy and Clinical Immunology (EAACI) and the Australian Society of Clinical Immunology and Allergy, developed clinical criteria (Table 1) for diagnosing anaphylaxis with 95\% sensitivity [6] (Table 1). PEF, Peak expiratory flow; BP, blood pressure. *Low systolic blood pressure for children is defined as less than $70 \mathrm{~mm} \mathrm{Hg}$ from 1 month to 1 year, less than (70 $\mathrm{mm} \mathrm{Hg}+[2 \mathrm{x}$ age $]$ ) from 1 to 10 years and less than $90 \mathrm{~mm} \mathrm{Hg}$ from 11 to 17 years. Although assessments of the incidence and prevalence of anaphylaxis is highly dependent on the population studied and the study design adapted, there is wide consensus on the increase in anaphylaxis prevalence, most specifically among populations residing in developed countries and particularly among the young age groups. There is no consensus yet as to the ultimate design to estimate the prevalence of anaphylaxis. The literature reflects on various approaches to studies aiming to assess prevalence and incidence of anaphylaxis with evaluations of their limitations. Studies have ranged from retrospective evaluations of medical records from allergologists, hospitalized patients in regular wards and in intensive care units and out-patient clinics to reviews of medication-dispensing databases on epinephrine auto injectors and finally, subjective assessments of patients or caregivers and guardians. Similarly, accurate incidence and prevalence is particularly diverse in consequence to the variable case definitions adopted and challenges of fluctuating frequencies in addition to increases in symptom severity.

Even though anaphylaxis has been on the rise for the past decade with reported rates of $350 \%$ increase among food induced and $230 \%$ increase among nonfood induced reactions [7], there is still paucity of data on the prevalence and outcome of anaphylaxis in various populations. The absence of a standardized definition for anaphylaxis has impeded research and further investigations into the epidemiology of the disease. It has hence, led to decreased diagnosis of the cases which in turn interfered with proper medical management of the patients [8]. Modest studies with debatable methodologies have been conducted in an attempt to estimate the prevalence of anaphylaxis worldwide. Incidence of anaphylaxis as per hospital admissions was estimated at 10.8 per 100,000 population for the period 1993 to 2005 in Australia [9], at 3.6 per 100,000 population for the period of 2005 to 2009 in the UK [10] with $0.3 \%$ of admissions being to adult wards and $0.1 \%$ to pediatric units [11] and at 1.95 per 100,000 population for the period 2010 to 2011 in Istanbul, Turkey [12]. However, literature suggests typical occurrence of anaphylactic reactions that do not require hospitalization which deems hospital admissions unreliable as a sole indicator for anaphylaxis incidence.

Incidence of anaphylaxis as per emergency units' records was estimated at $0.82 \%, 0.34 \%$ and $0.1 \%$ in Canada [13], US [13] and Australia [14] respectively. There was no standardized case definition described in the methodologies of these studies which poses a number of limitations and biases. Moreover, rate of anaphylaxis in Seoul, Korea for the period 2000 to 2006 was estimated at $0.014 \%$ based on data collected from emergency units, out patients and hospital admissions [15] and at 6.7\% and 7.9\% in England for the years 2001 and 2005 respectively based on data collected from primary healthcare centers [16]. Data collected from Seattle, US database assessed anaphylaxis incidence characterized by urticarial or angioedema at 10.5 per 100,000 population for the period 1991 to 1997 [17]. Another retrospective study conducted in Olmsted County, limited by the sole inclusion of middle class Caucasian population, estimated the incidence at 49.8 per 100,000 per year [18]. Epinephrine procurement was also used as an indicator for anaphylaxis incidence in a five year study in Canada although epinephrine can be prescribed for simple food allergies posing a risk of overestimation of the prevalence of anaphylaxis. Prevalence based on prescriptions ranged between $1.44 \%$ among those less than 17 years of age to $0.90 \%$ among those $17-64$ years of age and $0.32 \%$ among those above 65 years old [19].

Another methodology relied on telephone investigations of anaphylaxis prevalence as per standard questionnaires. Prevalence as per parents of children between 3 to 17 years old in South Australia was $0.59 \%$ [20] $5 \%$ as per adults known to have food allergies in Italy [21] and $0.13 \%$ per year based on patients' reports in Piemont, Italy [22]. These studies are limited by inclusion of high risk groups, recall biases, subjectivity of individual severity assessment and lack of medical record confirmation. Several studies aimed at estimating the prevalence and incidence of targeted allergen inducing anaphylaxis, namely food, medications, drugs, latex and insect prickles. Similar to studies on prevalence of general anaphylaxis, estimations of prevalence of specific allergen inducing anaphylaxis has varied through literature. For instance, literature on rate of food-induced anaphylaxis as per data from retrospective reviews of medical records and reviews of inpatient and outpatient records has resulted in a range of estimations from 0.1 per 10,000 to 7 per 10,000 ; moreover, a range of $13 \%$ to $65 \%$ of anaphylaxis cases in the population have been attributed to food triggers [23]. Although cases of unidentified anaphylaxis and multifactorial anaphylaxis exist, the most common trigger of anaphylactic reactions in children is food proteins such as milk, egg, wheat, soy, peanuts, tree nuts, fish and shellfish. Insect bites of bees, wasps or jumper ants and drugs are also typical triggers in children [24]. Hospital admissions following anaphylaxis are not unusual among children; however, children mortality attributed to anaphylaxis is infrequent [25].

Food allergy is a multisystem allergic reaction characterized by a rapid inception and progression following exposure to a food protein [26]. Incidence of food-allergy induced anaphylaxis peaks during the first 2 years of age and progressively decreases through life. All foods can be considered anaphylaxis causing allergens; however, anaphylaxis in children is most significantly attributed to milk, egg, wheat, soy, peanuts, tree nuts, fish and shellfish. Although allergies to milk, egg, wheat and soy diminish by age, allergies to peanut, tree nuts, fish and shellfish are considered ultimately permanent [27]. Globally, prevalence of food allergy, which results in a significant fraction of anaphylaxis and other severe reactions, ranges between 5 to $8 \%$ in children and is estimated at $1.5 \%$ in the general popula- 
tion [28]. Literature reports increasing trends in food allergy [29] however, it is yet to be determined if the increase reveals a true rise in the number of cases, an improved awareness in the societies or enhanced diagnosis [30]. In a global survey of changing patterns of food allergy reviewing data collected from 89 countries, it was reported that the majority of countries reported an increase in the prevalence of food allergy in the last decade based on information gathered from healthcare burden [31].

Several studies assessed the prevalence of food allergies and food-induced anaphylaxis as per parental perception. A European multicountry study reported prevalence of food allergy at 5\% with the highest rates among 2 to 3 years old [32]. Another study estimated that $28 \%$ of children in the US had at least one adversative response to food [33] while a study in Denmark estimated that $7 \%$ of children under one year of age had adverse reactions following the ingestion of cow milk [34]. It is however widely known that public perception of food allergy is overestimated when compared to physician diagnosed disease. For instance, only $5 \%$ of the children in the US perceived to have an adverse reaction to food were confirmed by a food challenge [33] while only $2 \%$ of the children perceived to have cow milk allergy in Denmark were confirmed by oral challenge [34]. Prevalence of food allergy among school children in France was reported to be $2 \%$ as per the records from allergy clinics [35]. Prevalence of food allergies in a population is highly dependent on the dietary traditions of the country. For instance, in children less than 5 years of age, egg allergy is common in Australia, New Zealand and Asia while cows' milk allergy is common in the Middle East; both allergies are common in Europe. In children more than 5 years of age, peanuts, tree nuts, seafood, egg and milk tend to be common in most regions; apple and kiwi allergies are common in Europe, Central and South America, peanut and nuts in Australia, Western Europe and USA, eggs in Eastern Europe, beef in Turkey and sesame in the Middle East [31].

Epidemiological studies assessing the prevalence of anaphylaxis in general and food allergy specifically are scarce in the Middle East. The global survey on food allergy conducted in 2013 reports Central and South America, Africa, Eastern Europe and the Middle East as the predominant regions where research data on prevalence of food allergy is deficient [31]. A cross-sectional study conducted in UAE showed that $8 \%$ of school children 6 to 9 years of age were diagnosed with food allergy by a clinician with eggs, fruits and fish constituting the main allergens. The study also showed a correlation between the food allergy episode, previous atopic diseases and a family history of food allergies [36]. Data on incidence and prevalence of anaphylaxis in the Eastern Mediterranean region is scarce in general and is almost absent in Kuwait in particular given the privation of a national anaphylaxis registry and the disagreement on a standard anaphylaxis definition among clinicians. This warrants increased efforts aiming to close this research gap in the light of the rapid increase of the rate of the disease and its life-threatening nature.

With emerging evidence on the high risk of anaphylaxis, most prominently food-induced anaphylaxis among the paediatric population, this study was conducted in Kuwait with the aim of collecting accurate epidemiologic data from children 3 to 18 years of age in order to assess the lifetime prevalence of anaphylaxis among the paediatric population, identify the most at risk age and evaluate the main trigger for the condition in children. Importance of similar research is reiterated and emphasized in the Global agenda for anaphylaxis research as per the World Allergy Organization anaphylaxis guidelines. This study will help appraise the magnitude of the situation in Kuwait and assess the management plans of children known to have at least one episode of anaphylaxis in terms of prescription and use of epinephrine auto-injector and having a written anaphylaxis emergency management plan that will help in preparing patients in the case of another acute anaphylactic reaction. Results of this study will help identify target population in need of directed awareness and themes of awareness campaigns in need to be conducted. Anaphylaxis management in schools presents distinctive challenges. Results of this study will also create evidence to substantiate the need to raise attention of school facilities to the magnitude of the condition and the need for eligible healthcare workers with sustainable trainings on anaphylaxis emergency management at school premises at all time, specifically in the light of the emerging evidence of food-induced anaphylaxis reactions reported outside homes in children. Awareness on anaphylaxis should also be directed to the community, among caregivers and healthcare workers which will in turn shed the light on effective therapeutic interventions and thus, enhance the care of patients with the condition by diminishing the risk of condition-attributable complications, morbidities and mortalities. It will also aid in reducing patient and relatives apprehensions and increase knowledge on effective prevention.

\section{Methodology}

A descriptive cross-sectional study with a multistage stratified cluster sampling of children aged three to eighteen was conducted. Kuwait is a small country located in the Arabian Gulf region with an approximate population of 3.5 million. $25 \%$ of the estimated Kuwaiti population is under nineteen years old of which almost 700,000 are students registered in nurseries, primary, intermediate and secondary schools distributed over the 6 governorates according to the ministry of Education for the school year 2015-2016.

First stage of the cluster sample was governorate sampling whereby two, namely Capital and Hawally governorates, out of the six governorates were chosen for the subsequent sampling of schools. Second stage sampling was stratified sampling of schools with a proportionate allocation to level of education in each region sampled. Subsequently, a total of 42 schools were selected for this study. 18 schools consisting of 2 nurseries, 8 primary, 4 intermediate and 4 secondary schools were chosen from the Capital city while 24 schools consisting of 2 nurseries, 10 primary, 5 intermediate, 4 secondary schools as well as 3 unspecified, 2 Indian and one Pakistani schools were chosen from Hawally city. The number of interviewed students in each school was allocated proportionate to the number of registered students in the respective school (Appendix 1).

2828 registered students of both genders and all nationalities in the selected governmental and private schools were sequential- 
ly recruited in the school years 2014-2015 and 2015-2016 over a period of 9 months to participate in the study. Sample size was calculated to attain an $80 \%$ power and $95 \%$ confidence interval, assuming $1 \%$ as the actual prevalence of anaphylaxis in Kuwait with $0.4 \%$ precision and accounting for around 19\% non-response. All children between 3 and 18 years of age were approached for recruitment. Children below 3 and above 18 years of age and those having special needs were excluded from the study. All eligible children were asked to participate in the study during the schools' parents-teachers meeting. Study objectives and methodology of interview were explained to the parents and children along with the right to participate or refuse to participate. Participants were reassured that refusing to participate will not affect their right of having full healthcare services, that anonymity and confidentiality of their participation is guaranteed and that they are free to opt out of the study at any time without the need for explanation. An informed consent form was signed by the parents or guardians of the participants agreeing to take part (Appendix 2).

Table 1: Clinical criteria for diagnosing anaphylaxis.

\section{Anaphylaxis is highly likely when any one of the following 3 criteria are fulfilled:}

Acute onset of an illness (minutes to several hours) with involvement of the skin, mucosal tissue, or both (eg, generalized hives, pruritus or flushing, swollen lips-tongue-uvula)

\section{AND AT LEAST ONE OF THE FOLLOWING}

a. Respiratory compromise (eg, dyspnea, wheeze-bronchospasm, stridor, reduced PEF, hypoxemia)

b. Reduced BP or associated symptoms of end-organ dysfunction (eg, hypotonia [collapse], syncope, incontinence)

Two or more of the following that occur rapidly after exposure to a likely allergen for that patient (minutes to several hours):

a. Involvement of the skin-mucosal tissue (eg, generalized hives, itchflush, swollen lips-tongue-uvula)

b. Respiratory compromise (eg, dyspnea, wheeze-bronchospasm, stridor, reduced PEF, hypoxemia)

c. Reduced BP or associated symptoms (eg, hypotonia [collapse], syncope, incontinence)

d. Persistent gastrointestinal symptoms (eg, crampy abdominal pain, vomiting)

Reduced BP after exposure to known allergen for that patient (minutes to several hours):

a. Infants and children: low systolic BP (age specific) or greater than 30\% decrease in systolic BP*

b. Adults: systolic BP of less than $90 \mathrm{~mm} \mathrm{Hg}$ or greater than $30 \%$ decrease from that person's baseline

Self-administered questionnaires consisting of 12 questions and demographic variables, namely age, gender and nationality, were then handed to the participants. Questions included information on history of acute onset of illness with skin and/or mucosal tissue signs, respiratory compromise, documented medical history of reduced blood pressure, persistent gastrointestinal symptoms, age of onset of incident, number of incidents, use of adrenaline auto-injector and trigger of the allergy attack (Appendix 3). As there is no validated questionnaire available for the assessment of anaphylaxis, a questionnaire was assembled for the purpose of this study and pilot-tested on 10 known medically diagnosed anaphylactic and 10 other non-anaphylactic children. Pilot testing aimed to test the suitability of the used terminologies and phrasing among a similar culture of interviewees, the analytic procedure and the overall response of participants known for their anaphylaxis outcome. It also served to estimate the time needed to fill-out the questionnaire. Results showed $100 \%$ sensitivity and $100 \%$ specificity of the questionnaire. Anaphylaxis was defined according to the clinical criteria for diagnosing anaphylaxis proposed during the Second National Institute of Allergy and Infectious Disease/Food Allergy and Anaphylaxis Network symposium in 2005 (Table 1).

Participants were diagnosed with probable anaphylaxis

a) if they had an acute onset of the illness with involvement of skin or mucosal tissue, along with respiratory compromise or reduced blood pressure or

b) if the participant had 2 or more of the following symptoms after exposure to a known allergen for that specific participant

i. history of severe allergic reaction with skin/mucosal tissue (e.g., hives, generalized itch/flush, swollen lips/tongue/ uvula)

ii. airway compromise (e.g., dyspnea, wheeze/bronchospasm, stridor, reduced PEF)

iii. reduced blood pressure or associated symptoms (e.g., hypotonia, syncope) and

iv. gastrointestinal symptoms (e.g., crampy abdominal pain, vomiting) or

c) if the participant had hypotension after exposure to a known allergen for that specific participant (minutes to hours). Hypotension is defined as age-specific low systolic blood pressure or $>30 \%$ drop in systolic blood pressure in infants and children or systolic a systolic blood pressure of less than $100 \mathrm{~mm}$ Hg or more than a $30 \%$ drop from their baseline in adults. Participants were diagnosed with likely anaphylaxis if they fulfilled the above criteria and were diagnosed by a physician.

Participants diagnosed with probable or likely anaphylaxis were re-interviewed via phone calls for confirmation and further investigation of the incident. Those who had more than one incident of anaphylaxis were asked about the details of their worst episode. Data was entered and analysed using the Statistical Package for Social Sciences (SPSS-22). Descriptive statistics were used to analyze the data. Categorical variables were expressed as frequency and percentages while normal continuous variables were expressed as means and standard deviations. Chi-Square test will be used to examine the relationship between having anaphylaxis and different demographic variables. The study followed the guidelines of the Medical Research Ethics Committee of the Kuwait Institute 
for Medical Specialization (KIMS). All the necessary approvals for carrying out the research were obtained. The Ethical Committee of the Kuwaiti Ministry of Health approved the research as well as the Ethics Committee of Southampton University, UK. Copies of the protocols were disseminated to all stakeholders and the purpose and importance of the research findings clarified. Permissions of the Deputy Minister of Health in Kuwait, as well as head of each of the selected schools were obtained. A written consent form (Appendix 2) elaborating on the purpose of the research, the right of participants to withdraw at any time of the study and their right to anonymity and confidentiality was prepared and signed by the participants' parents before filling in the questionnaires. Collected data from the survey was consolidated in the principle investigator's clinic at New Mowasat Hospital and the data file was stored password protected on the computer all throughout the research course. The study was supported by the University of Southampton, UK and was carried in the State of Kuwait.

Table 2: Distribution of participating students with and without anaphylaxis history according to personal characteristics.

\begin{tabular}{|c|c|c|c|c|c|}
\hline \multicolumn{6}{|c|}{ Anaphylaxis History } \\
\hline \multirow[b]{2}{*}{ Variable } & \multicolumn{2}{|c|}{ Negative for Anaphylaxis $(n=2816)$} & \multicolumn{2}{|c|}{ Positive for Anaphylaxis $(n=12)$} & \multirow{2}{*}{$\begin{array}{c}\text { Test of significance } \\
\text { P-Value }\end{array}$} \\
\hline & Freq & $\%$ & Freq & $\%$ & \\
\hline \multicolumn{6}{|l|}{ Age (years) } \\
\hline$<6$ & 301 & 10.7 & 4 & 33.3 & \multirow{4}{*}{0.057} \\
\hline 06-Dec & 1744 & 61.9 & 7 & 58.3 & \\
\hline $13-15$ & 440 & 15.6 & 1 & 8.3 & \\
\hline$\geq 15$ & 331 & 11.8 & 0 & 0 & \\
\hline Mean \pm SD & $10.0 \pm 3.8$ & & $6.5 \pm 3.0$ & & \\
\hline Min - Max & $3.0-18.0$ & & $3.0-14.0$ & & \\
\hline \multicolumn{6}{|l|}{ Gender: } \\
\hline Males & 1042 & 37 & 7 & 58.3 & \multirow[t]{2}{*}{0.127} \\
\hline Females & 1774 & 63 & 5 & 41.7 & \\
\hline \multicolumn{6}{|l|}{ Nationality: } \\
\hline Kuwaiti & 2345 & 83.3 & 9 & 75 & \multirow[t]{2}{*}{0.444} \\
\hline Non-Kuwaiti & 471 & 16.7 & 3 & 25 & \\
\hline \multicolumn{6}{|c|}{ Number of siblings: } \\
\hline 1 & 158 & 5.6 & 0 & 0 & \multirow{3}{*}{0.647} \\
\hline 2 & 545 & 19.4 & 3 & 25 & \\
\hline$\geq 3$ & 2133 & 75 & 9 & 75 & \\
\hline \multicolumn{6}{|c|}{$\begin{array}{l}\text { Birth order among } \\
\text { siblings: }\end{array}$} \\
\hline $1 \mathrm{st}$ & 755 & 26.8 & 1 & 8.3 & \multirow{3}{*}{0.095} \\
\hline 2nd & 817 & 29 & 2 & 16.7 & \\
\hline$\geq 3 \mathrm{rd}$ & 1244 & 44.2 & 9 & 75 & \\
\hline
\end{tabular}

\section{Results}

The overall prevalence of anaphylaxis in the study population was 4.24 per 1000 with a $95 \%$ confidence interval of $1.85-6.64$ per 1000 population. A total of $12(0.42 \%)$ participants fulfilled all the criteria for diagnosing probable anaphylaxis, out of which $66.7 \%$ were diagnosed during the incidence by a medical physician. Chi-squared analysis of difference between the population positive for anaphylaxis and negative for anaphylaxis on demographic variables was conducted. $83.3 \%$ of children negative for any history of anaphylaxis and $75.0 \%$ with a history of anaphylaxis were Kuwaiti. $63.0 \%$ of children negative for any history of anaphylaxis and $41.7 \%$ with a history of anaphylaxis were females. Mean age of children negative for any history of anaphylaxis was $10 \pm 3.8$ while it was $6.5 \pm 3.0$ for those with a history of anaphylaxis. $75.0 \%$ of children negative and those positive for any history of anaphylaxis had 3 or more siblings. $44.2 \%$ of those negative and $75.0 \%$ of those positive for any history of anaphylaxis and were ranked 3 or more in the birth order among siblings. 
Table 3: Distribution of participating students with anaphylaxis history according to clinical characteristics.

\begin{tabular}{|c|c|c|}
\hline Variable & Frequency & $\%$ \\
\hline Number of severe allergic attacks: & & \\
\hline Once & 7 & 58.3 \\
\hline Twice & 4 & 33.3 \\
\hline$>2$ & 1 & 8.3 \\
\hline History of sudden onset of illness: & & \\
\hline Skin & 5 & 41.7 \\
\hline Mucosal tissue & 1 & 8.3 \\
\hline Both & 6 & 50 \\
\hline Age during incident (year): & & \\
\hline $0-1$ & 4 & 33.3 \\
\hline 02-Apr & 4 & 33.3 \\
\hline 05-Nov & 4 & 33.3 \\
\hline Sudden respiratory signs and symptoms:* & & \\
\hline No & 3 & 25 \\
\hline Shortness of breath & 6 & 50 \\
\hline Hypoxemia & 2 & 16.7 \\
\hline Wheezes & 2 & 16.7 \\
\hline Stridor & 3 & 25 \\
\hline Sudden reduced blood pressure:* & & \\
\hline No & 10 & 83.3 \\
\hline Hypotonia & 1 & 8.3 \\
\hline Fainting & 1 & 8.3 \\
\hline Incontinence & 1 & 8.3 \\
\hline Sudden gastrointestinal symptoms:* & & \\
\hline No & 1 & 8.3 \\
\hline Cramping abdominal pain & 9 & 75 \\
\hline vomiting & 4 & 33.3 \\
\hline
\end{tabular}

There was no significant statistical difference between those having history of anaphylaxis and those who haven't on age ( $p$-val$\mathrm{ue}=0.057)$, gender $(\mathrm{p}$-value $=0.127)$, nationality ( $\mathrm{p}$-value $=0.444)$, number of siblings ( $\mathrm{p}$-value $=0.647$ ) and birth order among siblings ( $p$-value $=0.095$ ) (Table 2). Out of those who met all the criteria for anaphylaxis, $58.3 \%$ had only one incidence of a severe allergic attack $33.3 \%$ had 2 incidences and $8.3 \%$ had more than 2 incidences of severe allergic attacks. 100\% had either skin and/or mucosal tissue involvement, $41.7 \%$ had skin involvement alone, $8.3 \%$ had mucosal tissue involvement alone and half (50.0\%) had an involvement of both skin and mucosal tissue. A total of $75.0 \%$ had a type of airway compromise ranging from $16.7 \%$ having hypoxemia, $16.7 \%$ having wheezes to $25.0 \%$ reporting stridor and $50.0 \%$ shortness of breath. $16.7 \%$ had a sudden reduced blood pressure whereby an equal percentage of $8.3 \%$ reported hypotonia, fainting and incontinence; however, there was no actual documentation of reduced blood pressure. Moreover, $91.7 \%$ had sudden gastrointestinal symptoms; $75.0 \%$ had cramping abdominal pain and one third (33.3\%) reported vomiting. Reported age of first incidence was principally in preschool age i.e. less than 4 years old. A total of 8 children $(66.6 \%)$ had their incidence at ages less or equal to 4 years, and 4 children (33.3\%) between the ages of 5 and 11 (Table 3 ) and (Figure 1). A total of $66.7 \%$ of the reported anaphylactic reactions were diagnosed during the acute incident by a physician and $8.3 \%$ had a recurring incident in the following 72 hours. A mere $41.7 \%$ of the children with a history of anaphylaxis reported being treated within the first 15 minutes of the onset of clinical symptoms, $16.7 \%$ between the first 15 and 30 minutes and $16.7 \%$ were treated after more than 2 hours. $25.0 \%$ of the anaphylactic children were not aware of the time they received treatment following the onset of their symptoms (Figure 1). Only 33.3\% reported being given an adrenaline auto-injector during their reaction (Figure 2). $58.3 \%$ reported neither having an adrenaline auto-injector nor holding a written anaphylaxis emergency plan (Figure 3). The rest of the $41.7 \%$ reported having an available adrenaline auto-injector but never using it, despite the fact that $60.0 \%$ of them have a history of recurring anaphylactic reactions.

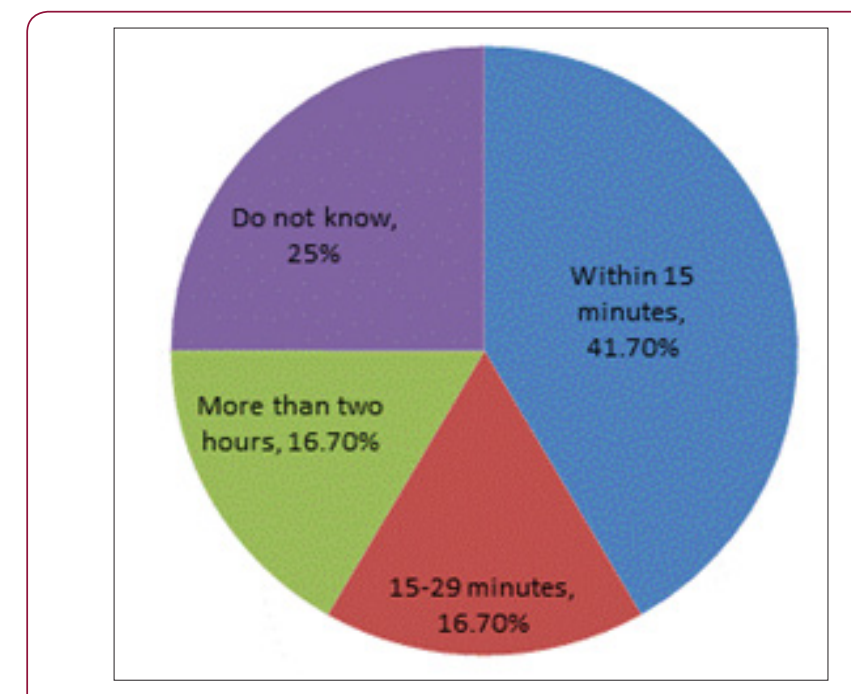

Figure 1: Percentage of patients with anaphylaxis by time lapse between treatment and anaphylaxis reaction onset.

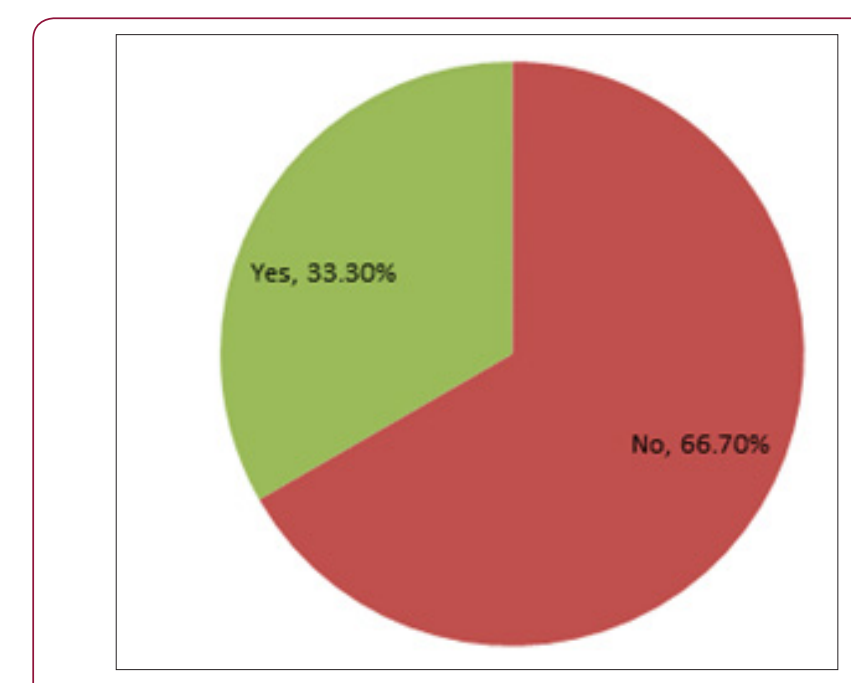

Figure 2: Percentage of patients given adrenaline autoinjector during reaction. 


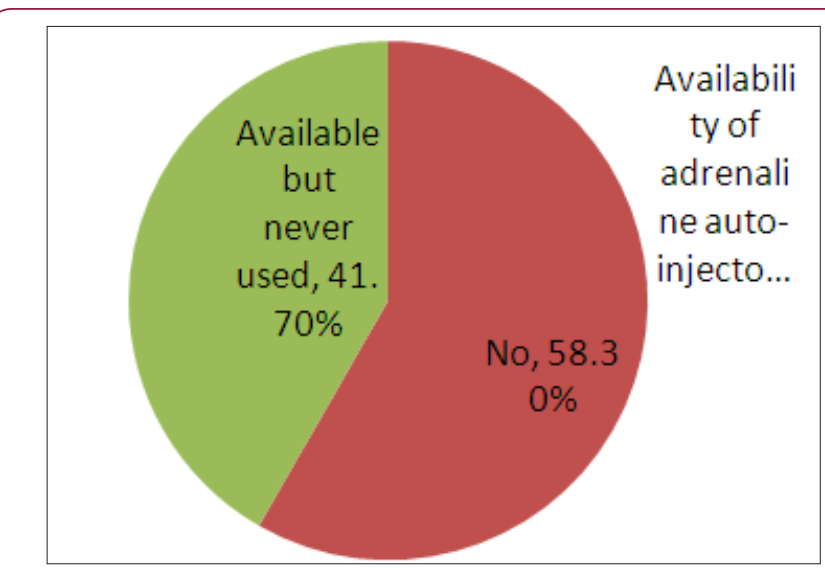

Figure 3: Percentage of patients with available adrenaline auto-injector

The duration of the reaction ranged from less than 1 hour in $50.0 \%$ of the children, 3 to 5 hours in $16.7 \%$ and it lasted more than 72 hours in $8.3 \%$ of the children. $25.0 \%$ of the children were not aware of the duration of their reaction (Table 4) and (Figure 4). As for the trigger of the allergy attack, food was the major trigger in $9(75.0 \%)$ children overall, of which nuts was the most common (33.3\%), followed equally by milk and eggs (16.7\%) and another $16.7 \%$ for other types of food. Medicine was the trigger in $2(16.7 \%$ ) of them and one was not sure of the trigger (Table 4). Food was also the main trigger in $6(75.0 \%)$ children whose incidence happened when they were less than 4 years old. In the latter population, 4 had reactions triggered by nuts, one was triggered by milk and one by eggs. The remaining reactions of the 2 children were triggered by medicine in one child and the final had an unknown trigger. As for the rest of the 4 children who were 5 to 11 years-old at the time of the anaphylactic reaction, food was the main trigger in $3(75.0 \%)$ of them and $1(25.0 \%)$ was due to medicine; none of them was due to nuts (Figure 1-6) and (Table 5).

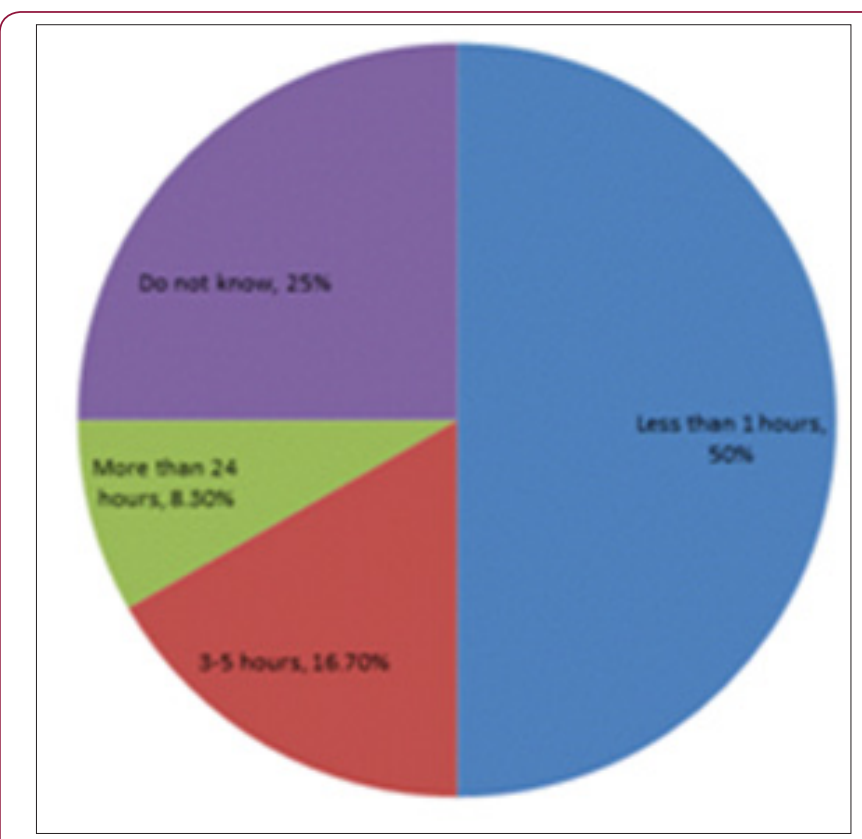

Figure 4: Percentage of patients by duration of reaction.

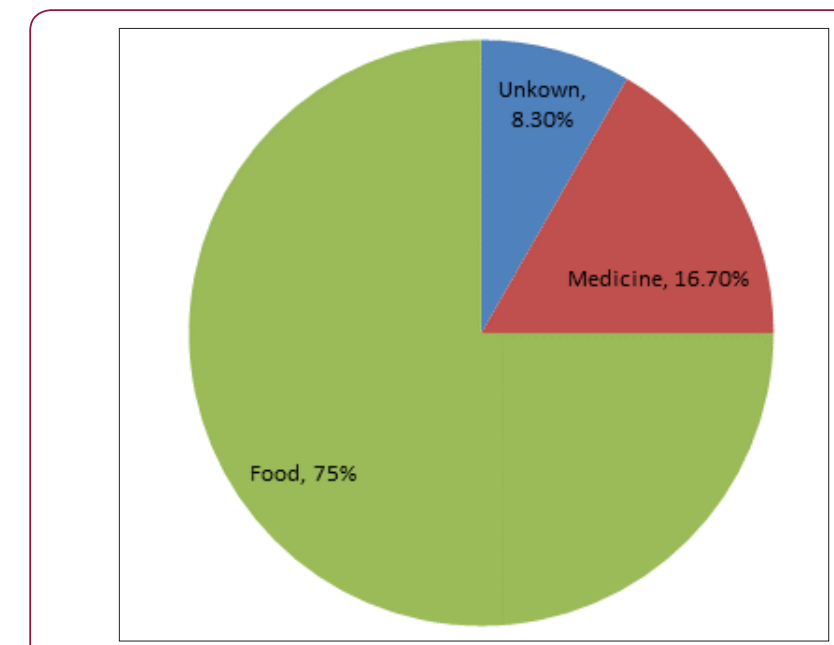

Figure 5: Percentage of anaphylaxis by trigger agent.

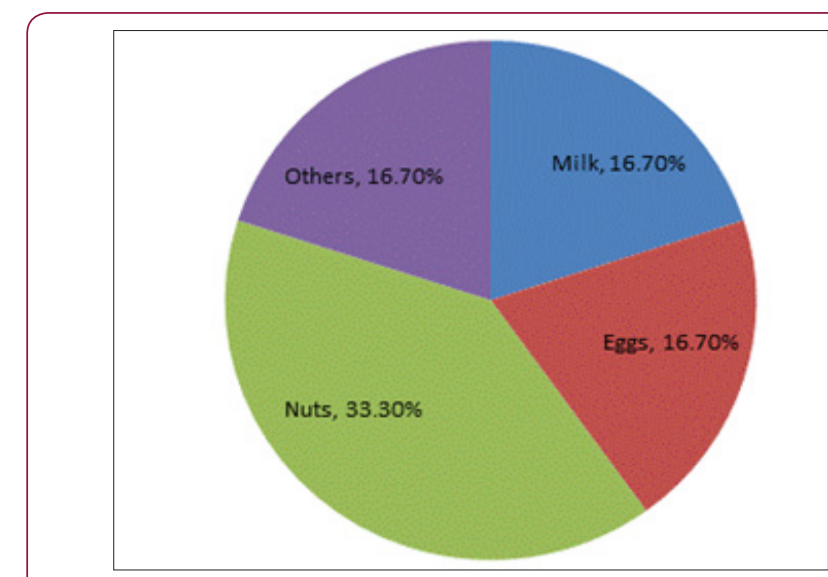

Figure 6: Percentage of food-induced anaphylaxis by type of food trigger.

Table 4: Distribution of participating students with anaphylaxix history according to management.

\begin{tabular}{|c|c|c|}
\hline Variable & Frequency & $\%$ \\
\hline \multicolumn{3}{|c|}{$\begin{array}{l}\text { Diagnosis as anaphylaxis during inci- } \\
\text { dent by doctor: }\end{array}$} \\
\hline No & 4 & 33.3 \\
\hline Yes & 8 & 66.7 \\
\hline \multicolumn{3}{|c|}{ Receiving treatment during incident: } \\
\hline Within 15 minutes & 5 & 41.7 \\
\hline $15-29$ minutes & 2 & 16.7 \\
\hline \multicolumn{3}{|c|}{ Given adrenaline auto injector: } \\
\hline No & 8 & 66.7 \\
\hline Yes & 4 & 33.3 \\
\hline \multicolumn{3}{|l|}{ Duration of reaction: } \\
\hline Less than 1 hours & 6 & 50 \\
\hline 3-5 hours & 2 & 16.7 \\
\hline More than 24 hours & 1 & 8.3 \\
\hline Do not know & 3 & 25 \\
\hline
\end{tabular}




\begin{tabular}{|c|c|c|}
\hline Reaction recurrence: & & \\
No & 11 & 91.7 \\
Within 72 hours & 1 & 8.3 \\
\hline Availability of adrenaline auto-injec- \\
tor: & & \\
No & 7 & 58.3 \\
Available but never used & 5 & 41.7 \\
\hline $\begin{array}{c}\text { Providing an anaphylaxis emergency } \\
\text { plan: }\end{array}$ & & \\
No & 7 & 58.3 \\
Yes & 5 & 41.7 \\
\hline
\end{tabular}

Table 5: Distribution of participating students with anaphylaxis history according to the trigger of the allergy attack.

\begin{tabular}{|c|c|c|}
\hline Variable & Frequency & \% \\
\hline Trigger agent: & & \\
Unknown & 1 & 8.3 \\
Medicine & 2 & 16.7 \\
Food & 9 & 75 \\
\hline Types of trigger food*: & 2 & 16.7 \\
Milk & 2 & 16.7 \\
Eggs & 4 & 33.3 \\
Nuts & 2 & 16.7 \\
Others & & \\
\hline
\end{tabular}

\section{Discussion}

This is the first epidemiological study to assess the prevalence of anaphylaxis in children in Kuwait. Lifetime prevalence of anaphylaxis was found to be 4.24 per 1,000 of the study population. This figure is consistent with a US study reporting an incidence of 3.4 per 1,000 population according to data collected from emergency units' records [13]. Interestingly enough, a similar study assessing the prevalence of anaphylaxis among children 3 to 17 years of age in South Australia also using a similar methodology relying on telephone investigations with parents regarding anaphylaxis prevalence as per standard questionnaires reported a close figure of 5.9 per 1,000 population [20]. Prevalence of anaphylaxis has varied throughout the literature depending on the methodology adapted. Prevalence of this study has also varied from other studies conducted in different parts of the world, most probably due to disparities in the study design, diagnostic criteria and the study population.

It was beyond the scope of this study to look at associated allergic diseases. Those who reported allergic reactions but did not fulfil the criteria of anaphylaxis as per the adopted definition from The Second National Institute of Allergy and Infectious Disease/ Food Allergy and Anaphylaxis Network symposium in 2005, was not considered as having a history of anaphylaxis because the investigation to ascertain the true nature of these reactions surpasses the capacity of this study. Risk factors for anaphylaxis, which may differ between adults and children populations, were not studied either. Those most commonly include asthma, atopic dermatitis and respiratory allergies. Asthma has been shown to be associated with a 4.0-fold increase in food allergies in children and it is well established that the more severe the respiratory involvement, the greater the risk of allergies and anaphylaxis [37]. Moreover, atopic dermatitis and respiratory allergies have also been associated with a 3 and 5-fold increase in anaphylaxis respectively [37]. Although severity of an anaphylactic reaction cannot be predicted based on past reactions or diagnostic/laboratory tests, comorbid asthma is the factor that is most often linked to severe reactions. Geographical factors also play a role, especially that anaphylaxis was found to be more prevalent in high altitude areas and areas with low sunlight, possibly indicating a role of vitamin D in the pathophysiology of the disease [38].

In non-hospital settings, food has been shown to be the most common cause for anaphylaxis in children, followed by insect venom and medications [39]. The prevalence of food anaphylaxis in children is relatively variable in the literature. It ranges from 2 to $27 \%$ in children less than 3 years old [40-43]. This is probably due to disparities in the adopted food allergy definition among various studies and the difficulties in performing challenge tests for confirmation of those food allergies [44-46]. Strategies of prevention are becoming more and more difficult, knowing the economic as well as the psychological burden resulting from such strategies. The amount of money needed to apply such preventions may sometimes exceed that needed to treat the resulting allergies and/or anaphylaxis. Another pitfall in handling food allergies is the fact that many children are exposed to allergens in an uncontrolled setting, such as schools and day care centres, and infants might be indirectly exposed through breastfeeding [39].Food anaphylaxis primarily affects young children and usually resolves with age. Findings of this study support the wide belief of food being the main trigger for anaphylaxis in children. Nuts were the main trigger in young children whose incidence occurred at or less than 4 years of age and none of the older children reported nuts induced anaphylaxis. Although allergies to milk, egg, wheat and soy diminish by age, allergies to peanut, tree nuts, fish and shellfish are considered ultimately permanent. However, tolerance to nuts has been reported in some studies [27]. Literature shows peanut and nut allergy to be common in Australia, Western Europe and USA in children older than 5 years of age but rare in Singapore and Italy [31]. Data collected from emergency wards in the US shows food-allergy induced visits every 3 minutes and a food-induced anaphylaxis visit every 6 minutes [47]. Food allergy is hence portrayed as an undervalued evolving condition that lacks suitable prevention methods.

In this study, only 2 children, $16.7 \%$ of the total children having a history of anaphylaxis reported the main trigger to be medicine. Anaphylaxis due to antibiotics is uncommon in children but skin eruption during time of antibiotic use is common which is most likely due to an underlying viral infection [48].

The findings of this study are extremely important for both, health care and educational providers. With a significant prevalence of 4.24 per 1,000 population and an appraised 700,000 children enrolled in schools in Kuwait, it can be projected that 2,970 
school children have a history of anaphylaxis. This necessitates the provision of adequate information and training of school staffs in order to be able to offer knowledgeable first aid to any child who might develop anaphylactic reaction during school hours given the lack of a standardized policy of first aid procedures in schools settings. The study also shows a delay in initiating treatment for anaphylactic patients whereby $16.7 \%$ of the patients were treated after more than 2 hours of onset. Delay could arise from undermining of the disease prognosis among parents and guardians leading to deferrals in seeking healthcare or due to miscategorizing anaphylaxis among priority ailments in the emergency rooms. In both cases, awareness on the need for immediate treatment of patients is highly needed among lay people to induce behavioural change and among healthcare workers for standardization of anaphylaxis as a top priority in emergency rooms. In $25.0 \%$ of the patients, parents were unaware of the time lapse between symptom onset and initiation of treatment. A similar percentage was unaware of the duration of their acute anaphylaxis reaction. This emphasizes a greater deal of unawareness of the patient and the caregivers of the impact of the condition on the health of the patient and substantiates the implications for the need of awareness campaigns directed towards behavioural change. Moreover, more than half of the children reported neither having an adrenaline auto-injector nor holding a written anaphylaxis emergency plan.

Also, although the rest of the $41.7 \%$ have an available auto-injector, they reported never using it despite of the fact that $60.0 \%$ of them have a history of recurring anaphylactic reactions. This has most probably arisen due to being treated by emergency physicians rather than being referred to allergologists. Hence, patients are not having a proper counselling or training on how to manage the future reaction. Introductory sessions on the management and treatment of anaphylaxis should be given to the parents, guardians and anaphylactic patients emphasizing the importance of an adrenaline auto-injector with training on the method of usage. More noticeably, adrenaline auto-injectors are not widely available in many countries, particularly in those countries that lack estimations on the burden of anaphylaxis in the population or have a service burden of allergy. Insufficient availability can arise either because of accessibility obstacles or because the government has not yet subsidized them [31].

Moreover, many countries do not yet have a consensus on a national anaphylaxis emergency management plan which leaves the option of providing a plan to the patient at the discretion of the allergologists. Countries with available, government subsidized auto-injectors and mostly standardized emergency plans are North America, Western Europe, Nordic countries and Oceania. However, Middle East, many Asian countries and South America, Africa and some regions in Eastern Europe don't have readily available adrenaline auto-injectors [31]. This has wide insinuations for continuous sustainable workshops for all individuals in the society whose role is to care, supervise, teach, or deal with children in general and those with food allergies specifically in light of the lack of anaphylaxis emergency plans. Observations emerging from this study substantiate the necessity for awareness among governments and health policy makers to initiate the formation of a standardized national anaphylaxis emergency plan and subsidize adrenaline auto-injectors in light of the implication and effect of food allergy principally in children. Health care policies should be directed towards better preparation for the expected increase in anaphylaxis and the rising need for health services, community awareness and capacity building to cope with this emerging global health issue.

\section{Conclusion}

In conclusion, this study highlights anaphylaxis as a significant pediatric health issue that has been increasing globally for the past decade and that is likely to increase further in the upcoming decade. In several developed countries, $10 \%$ of infants have proven food allergy as per gold standards subsequent to the increase witnessed in the past decade [49]. Projections indicate comparable patterns in the developing countries [50]. The study also exposes the scarcity of reliable data and the need for further research on the prevalence and impact of anaphylaxis in both, developed and developing countries. Recommendations on way forward emphasize the importance of ensuring that health care providers in the emergency units, as well as other health centers and school staffs are able to recognize the anaphylaxis episode and provide adequate first aid management as well as a clear written anaphylaxis emergency action plan for management of future reactions and that governments and health policy makers initiate the formation of policies that would be capable of handling the anticipated health and economic burden posed by the increased prevalence of anaphylaxis and the rising need for health services with regards to this emerging global health issue. Anaphylaxis in children population is in many ways different than that in the adult population, and hence requires different considerations. Comorbidities, as well as risk factors and clinical signs and symptoms, are dissimilar between those populations; furthermore, there are distinguished features within the pediatric age range itself. For instance, symptoms may not be well expressed in preverbal children. Another important issue in this age group is the continuously increasing independence of teenagers and adolescents, as well as peer pressure, which result in more exposure to meals outside home, and an increased risk-taking behavior and noncompliance to carry an epinephrine auto injector. Another problem with compliance to epinephrine auto injector is the setting in which children are situated and the friendliness of the setting with the use of EAI, i.e., schools and daycare centers. Moreover, compliance can differ when the patient is not accompanied by the person who usually gives them the injection, be it a parent, or a caregiver. Another feature that distinguishes the pediatric age group is the exposure to different vaccines, which affects the prevalence of anaphylaxis in this age group especially in those allergic to eggs [1].

All of the above mentioned characteristics make anaphylaxis in children a stimulating and challenging subject requiring targeted studies, starting with those assessing the prevalence of this emerging serious disease, to those highlighting the lack of availability, utilization and correct use of the treatment and the necessity of an emergency action plan. The design of the study carries 
several limitations. The study has a retrospective nature which innately carries a number of limitations. Also, information on the anaphylactic incidence is gathered from the parents; sensitivity of the data highly depends on parents recalling the exact details of the incidence. Therefore, information is subject to possible recall bias, specifically for the detailed history of every individual incidence. Moreover, all questions assessing the details of the anaphylactic reaction incidence only examine the worst reaction for those who had more than one reaction. Hence, the questionnaire could not provide information about the details of each reaction.

The prevalence reported in this study is only generalizable to school age children and to those children actually attending schools and does not reflect the actual prevalence of all children population as the study did not cover those children younger than 3 years old nor those not attending schools. Finally, the exact prevalence of anaphylaxis among non-Kuwaiti children may have been jeopardized by the sampling strategy. Non Kuwaiti children are not homogeneously distributed in private schools in Kuwait in spite of the high number of private schools included in this study. Furthermore, the turn-over of non-Kuwaiti nationality is rather high in Kuwait as there is no facility of permanent residency by law. Consequently, it was not possible to recruit an exact proportionate number of this population which might have biased the exact prevalence of anaphylaxis among the non-Kuwaiti nationality.

\section{References}

1. Chipps BE (2013) Update in Pediatric Anaphylaxis: A Systematic Review. Clinical Pediatrics 52(5): 451-461.

2. Simons FE, Ardusso LR, Bilo MB, El-Gamal YM, Ledford DK, et al. (2011) World Allergy Organization anaphylaxis guidelines: summary. J Allergy Clin Immunol 127(3): 587-593.

3. Boyce JA, Assaad A, Burks AW, Stacie M Jones, Hugh A Sampson, et al. (2010) Guidelines for the diagnosis and management of food allergy in the United States: report of the NIAID-sponsored expert panel. JAllergy Clin Immunol 126(6): S1-S58.

4. Sampson HA, Munoz-Furlong A, Bock SA, Schmitt C, Bass R, et al. (2005) Symposium on the definition and management of anaphylaxis: summary report. J Allergy Clin Immunol 115(3): 584-591.

5. Sampson HA, Munoz-Furlong A, Campbell RL, Adkinson NF, Bock SA, et al. (2006) Second symposium on the definition and management of anaphylaxis: summary report-second National Institute of Allergy and Infectious Disease/Food Allergy and Anaphylaxis Network symposium.J Allergy ClinImmunol 117(2): 391-397.

6. Panesar SS, Javad S, de Silva D, Nwaru BI, Hickstein L, et al. (2013) The epidemiology of anaphylaxis in Europe: a systematic review 68(11): 1353-1361.

7. Liew WK, Williamson E, Tang ML (2009) Anaphylaxis fatalities and admissions in Australia. J Allergy Clin Immunol 123(2): 434-442.

8. Bohlke K, Davis RL, DeStefano F, Marcy SM, Braun MM, et al. (2004) Vaccine Safety DatalinkTeam.Epidemiology of anaphylaxis among children and adolescents enrolled in a health maintenance organization. J Allergy Clin Immunol 113(3): 536-542.

9. Poulos LM, Waters AM, Correll PK, Lob-lay RH, Marks GB (2007) Trends in hospitalizations for anaphylaxis, angioedema, and urticaria in Australia, 1993-1994 to 2004-2005. J Allergy Clin Immunol; 120(4): 878-884.

10. Gupta R, Sheikh A, Strachan DP, Ander-son HR (2007) Time trends in allergic disorders in the UK. Thorax 62(1): 91-96.
11. B Gibbison, A Sheikh, P McShane, C Haddow, J Soar (2012) Anaphylaxis admissions to UK critical care units between 2005 and 2009. Anaesthesia 67(8): 833-839.

12. Cetinkaya F, Incioglu A, Birinci S, Karaman BE, Dokucu AI, et al. (2013) Hospital admissions for anaphylaxis in Istanbul, Turkey. Allergy 68(1): 128-130.

13. Kane KE, Cone DC (2004) Anaphylaxis in the prehospital setting. J Emerg Med 27(4): 371-377.

14. Braganza SC, Acworth JP, Mckinnon DR, Peake JE, Brown AF (2006) Paediatric emergency department anaphylaxis: different patterns from adults. Arch Dis Child 91(2): 159-163.

15. Yang MS, Lee SH, Kim TW, Kwon JW, Lee SM, et al. (2008) Epidemiologic and clinical features of anaphylaxis in Korea. Ann Allergy Asthma Immunol 100(1): 31-36.

16. Aziz Sheikh, Julia Hippisley-Cox, John Newton, Justin Fenty (2008) Trends in national incidence, lifetime prevalence and adrenaline prescribing for anaphylaxis in England. JRSocMed 101(3): 139-143.

17. Bohlke K, Davis RL, DeStefano F, Marcy SM, Braun MM, et al. (2004) Epidemiology of anaphylaxis among children and adolescents enrolled in a health maintenance organization. J Allergy ClinImmunol 113(3): 536-542.

18. Decker WW, Campbell RL, Manivannan V, Luke A, St Sauver JL, et al. (2008) The etiology and incidence of anaphylaxis in Rochester, Minnesota: a report from the Rochester Epidemiology Project. J Allergy Clin Immunol 122(6): 1161-1165.

19. Simons FE, Peterson S, Black CD (2002) Epinephrine dispensing patterns for an out-of hospital population: a novel approach to studying the epidemiology of anaphylaxis. J Allergy Clin Immunol 110(4): 647651.

20. CA Boros, D Kay and MS Gold (2000) Parent reported allergy and anaphylaxis in 4173 South Australian children. J. Paediatr. Child Health 36(1): 36-40.

21. R Aseroa, Antonicelli L, Arena A, Bommarito L, Caruso B, et al. (2009) Causes of Food-Induced Anaphylaxis in Italian Adults Int Arch Allergy Immunol 150(3): 271-277.

22. Giovanni Rolla, Mietta S, Raie A, Bussolino C, Nebiolo F, et al. (2013) Incidence of food anaphylaxis in Piemonte region (Italy): data from registry of Center for Severe Allergic Reactions, Intern Emerg Med 8(7): 615-620.

23. Wood RA, Camargo CA, Lieberman P, Sampson HA, Schwartz LB, et al. (2014) Anaphylaxis in America: The prevalence and characteristics of anaphylaxis in the United States. J Allergy Clin Immunol 133(2): 461467.

24. Wiggin CA, Dykewicz MS, Paterson R (1989) Idiopathic anaphylaxis: a review. Ann. Allergy 62(1): 1-4.

25. Harvey P, Sperber S, Kette F, Heddle RJ, Roberts-Thomson PJ (1984) Beesting mortality in Australia. MJA 140(4): 209-211.

26. Leung DYM, Sampson HA, Geha RS, Szefler SJ (2003) Pediatric Allergy: Principles and Practice. St. Louis, Mosby.

27. Wang J, Sampson HA (2007) Food anaphylaxis. Clin Exp Allergy 37: 651660 .

28. Grammer LC, Greenberger PA (2003) Patterson's Allergic Diseases. LWW (6 $6^{\text {th }}$ edn.).

29. Kagan RS (2003) Food allergy: an overview. Environ Health Perspec 111(2): 223-225.

30. Mosges R (2002) The increasing prevalence of allergy: a challenge for the physician. Clin Exp Allergy Rev 2(1): 13-17.

31. Prescott SL, Pawankar R, Allen KJ, Campbell DE, Sinn JKH, et al. (2013) A global survey of changing patterns of food allergy burden in children. World Allergy Organization Journal 6(1): 21. 
32. Steinke M, Fiocchi A, Kirchlechner V, Ballmer-Weber B, Brockow K, et al. (2007) REDALL study consortium: Perceived food allergy in children in 10 European nations. A randomised telephone survey. Int Arch Allergy Immunol 143(4): 290-295.

33. Bock SA (1987) Prospective appraisal of complaints of adverse reactions to foods in children during the first 3 years of life. Pediatrics 79(5): 683688.

34. Host A, Halken S (1990) A prospective study of cow milk allergy in Danish infants during the first 3 years of life. Clinical course in relation to clinical and immunological type of hypersensitivity reaction. Allergy 45(8): 587-596.

35. Penard-Morand C, Raherison C, Kopferschmitt C, Caillaud D, Lavaud F, et al. (2005) Prevalence of food allergy and its relationship to asthma and AR in schoolchildren. Allergy 60(9): 1165-1171.

36. S Al-Hammadi, F Al-Maskari, R Bernsen (2010) Prevalence of Food Allergy among Children in Al-Ain City, United Arab Emirates. Int Arch Allergy Immunol 151(4): 336-342.

37. Burks AW, Jones SM, Boyce JA, Sicherer SH, Wood RA, et al. (2011) NIAIDSponsored 2010 Guidelines for managing food allergy: applications in the pediatric population. Pediatrics 128(5): 955-965.

38. Koplin JJ, Martin PE, Allen KJ (2011) An update on epidemiology of anaphylaxis in children and adults. Curr Opin Allergy Clin Immunol 11(5): 492-496.

39. Boros CA, Kay D, Gold MS (2000) Parent reported allergy and anaphylaxis in 4173 South Australian children.J. Paediatr. Child Health 36(1): 36-40.

40. Nicklas RA, Bernstein IL, Li JT, et al. (1998) The diagnosis and management of anaphylaxis. J. All. Clin. Immunol 101(6): S465-S528.
41. Sampson HA, Burks AW (1996) Mechanisms of food allergy. Annu Rev Nutr 16: 161-77.

42. Bock SA (1987) Prospective appraisal of complaints of adverse reactions to foods in children in the first 3 years of life. Pediatrics 79(5): 683-688.

43. Chandra RK (1997) Food hypersensitivity and allergic disease: a selective review. Am. J. Clin. Nutr 66(2): S526-S529.

44. Kajosaari M (1982) Food allergy in Finnish children aged 1-6 years. Acta Paediatr. Scand 71(5): 815-819.

45. Sampson HA (1997) Food Allergy. JAMA 278: 188-94.

46. Polanco I (1992) Current status of digestive intolerance to food protein. J. Pediatr 121(5): S108-S110.

47. Sicherer SH, Leung DY (2012) Advances in allergic skin disease, anaphylaxis, and hypersensitivity reactions to foods, drugs, and insects in 2011. J Allergy Clin Immunol 129(1): 76-85.

48. Rieder MJ (1994) Mechanism of unpredictable adverse drug reactions. Drug Safety 11(3): 196-212.

49. Osborne NJ, Koplin JJ, Martin PE, Gurrin LC, Lowe AJ, et al. (2011) Prevalence of challenge-proven IgE-mediated food allergy using population-based sampling and predetermined challenge criteria in infants. J Allergy Clin Immunol 127(3): 668-676.

50. Leung TF, Yung E, Wong YS, Lam CW, Wong GW (2009) Parentreported adverse food reactions in Hong Kong Chinese pre-schoolers: epidemiology,clinical spectrum and risk factors. Pediatr Allergy Immunol 20(4): 339-346.

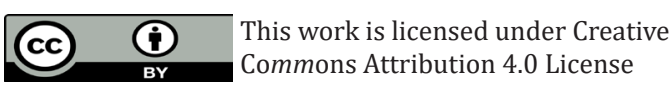

Submission Link: https://biomedres.us/submit-manuscript.php

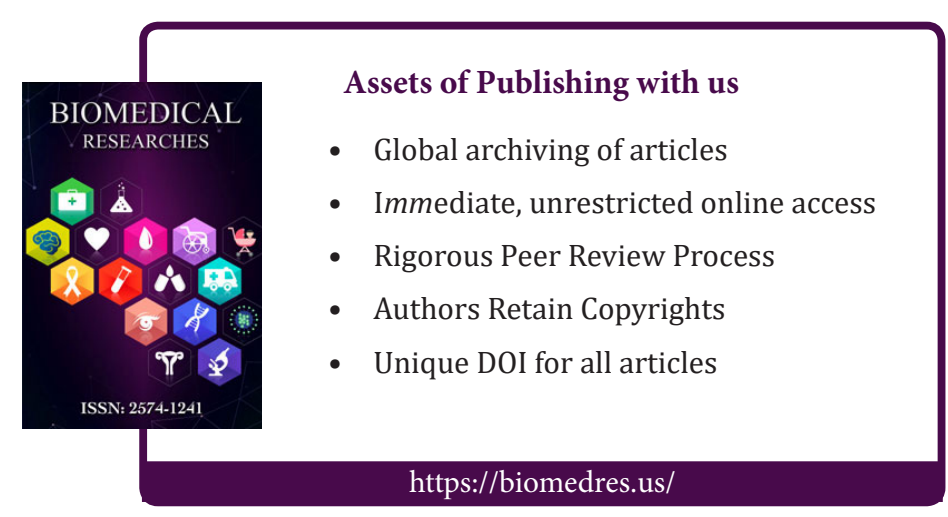

